\title{
Top Ten Tips Palliative Care Clinicians Should Know About Caring for Jewish Patients
}

\author{
Leah B. Rosenberg, MD, ${ }^{1}$ Eric R. Goodlev, MD, ${ }^{2}$ Rabbi Shulamit E. Izen, MAHL, ${ }^{3}$ Samantha L. Gelfand, MD, \\ Cantor Lauren Goodlev, MSM, ${ }^{5}$ Rabbi Benjamin Lanckton, MHL, ${ }^{3}$ Lara M. Skarf, MD, \\ Andrea Wershof Schwartz, MD, MPH, ${ }^{7-9}$ Christopher A. Jones, MD, MBA, ${ }^{10}$ and James A. Tulsky, MD ${ }^{4}$
}

\begin{abstract}
Judaism, one of the world's oldest religions, claims an estimated 14.3 million members worldwide. There is great diversity in terms of identity, practice, and belief among people who identify as Jewish. As of 2017, 40\% of the global Jewish community resided in the United States, making it essential for palliative care clinicians to understand religious and cultural issues related to their serious illness care. In this article, we will discuss 10 important concepts relevant to the inpatient care, advance care planning, and bereavement needs of Jewish patients and families.
\end{abstract}

Keywords: chaplaincy; Judaism; palliative care; spirituality

\section{Introduction}

$\mathbf{T}$ HE AMERICAN JEWISH COMMUNiTY numbered roughly 7.5 million in 2019 and has grown by $10 \%$ since 2012 . Relevant to palliative care, Jewish Americans are older than average and $26 \%$ are $\geq 65$ years. To help palliative care clinicians address the needs of Jewish patients coping with serious illness, this article through 10 high-yield tips highlights the diversity one is likely to encounter with regard to pertinent aspects of identity, belief, and practice.

\section{Tip 1: Judaism is More Than a Religion and} Encompasses Culture, Identity, and Ethnicity

Judaism has always included a wide variety of communities, beliefs, and practices; or, as the saying goes, "two Jews, three opinions." "Iudaism's core texts are the first five books of the Hebrew Bible known as the Torah. The Talmud, a 63-volume commentary on the Torah, presents ancient rabbinic teachings and debates on a wide array of ethical and legal issues. There is no central authority and autonomy is left to individual rabbis, communities, and Jewish people for decisions related to health care and serious illness.

Jews share distinctive customs, traditions, multiple spoken languages (e.g., Yiddish, Ladino, and Modern Hebrew) and a holy land also considered a national home (Israel).

Most Jews in America, if they do affiliate with a movement, adhere to one of five groupings (Orthodox, Conservative, Reform, Renewal, and Reconstructionist) although many would say they are "just Jewish." When providing medical care to Jewish patients, the specific version of Judaism they do, or do not, observe may affect their care, as described hereunder.

\section{Tip 2: Jewish Patients May Observe the Sabbath with Some Practices Affecting Medical Care}

The Book of Genesis describes the Sabbath day (Shabbat) as a separate and holy day of rest from work, lasting from

\footnotetext{
${ }^{1}$ Division of Palliative Care and Geriatric Medicine, ${ }^{3}$ Spiritual Care Department, Massachusetts General Hospital, Boston, Massachusetts, USA.

${ }^{2}$ Division of Palliative Care, Department of Medicine, Einstein Medical Center Montgomery, East Norriton, Pennsylvania, USA.

${ }^{4}$ Department of Psychosocial Oncology and Palliative Care, Dana-Farber Cancer Institute and Brigham and Women's Hospital, Boston, Massachusetts, USA.

${ }^{5}$ Beth David Reform Congregation, Gladwyne, Pennsylvania, USA.

${ }^{6}$ Division of Geriatrics and Palliative Care, Department of Medicine, ${ }^{7}$ New England Geriatric Research, Education and Clinical Centers, Veterans Affairs Boston Healthcare System, Boston, Massachusetts, USA.

${ }_{9}^{8}$ Department of Medicine/Division of Aging, Brigham and Women's Hospital, Boston, Massachusetts, USA.

${ }^{9}$ Harvard Medical School, Boston, Massachusetts, USA.

${ }^{10}$ Department of Medicine, Duke University School of Medicine, Durham, North Carolina, USA

Accepted September 15, 2020.
} 
sundown on Friday to sundown on Saturday. ${ }^{2}$ There is a wide range of Sabbath observance. Some Jewish patients may appreciate an opportunity to light Shabbat candles on Friday nights (usually battery-operated in the hospital), recite blessings over wine or grape juice and a braided bread called challah, and participate in prayer services. Sabbath practice can affect medical care as some Jews abstain from using electronic devices such as telephones or computers and avoid writing, even signing documents. Although there is a general Jewish legal principle that saving a life overrides Sabbath observance ( pikuach nefesh, see Tip 4), there is considerable debate around which activities are considered life-sustaining. ${ }^{3}$ Family members observing the Sabbath may not answer the phone or may seek a place to stay within walking distance from the hospital as many individuals do not drive or use public transportation for the 25 hours of Shabbat. In addition, patients or family members may wish to complete any monetary transactions or nonurgent matters before sunset on Friday.

\section{Tip 3: Some Jewish Patients Have Dietary Preferences or Restrictions Related to Keeping Kosher}

Although Jewish dietary practices vary greatly, clinicians should be aware of basic principles of Kosher laws (kashrut) that outline permitted and forbidden foods and appropriate food preparation. Common practice includes separation of meat and dairy products in the same meal, avoidance of nonkosher meat (namely from animals with cloven hooves or who do not chew cud, such as pigs), and avoidance of shellfish and other sea creatures without fins and scales. Many hospitals provide kosher food to patients upon request or families may bring in their own meals.

Kosher laws may be interpreted differently by Jewish communities. To identify implications for patient care, clinicians should ask patients if and how their dietary practices may influence their medical decisions or experience in a hospital. ${ }^{4}$ Survey data suggest that most Jewish patients will accept therapies that may violate dietary laws if needed to treat illness, reduce suffering, and prevent death. ${ }^{5,6}$ However, some Jewish patients may wish to consult with their rabbis about this on a case-by-case basis.

\section{Tip 4: The Value of Saving a Life (pikuach nefesh) May Have Implications for the Use of Life-Prolonging Interventions}

Among the foundational principles of Judaism, the saving of human life (pikuach nefesh) stands as perhaps the most fundamental. ${ }^{7}$ For example, the principle of pikuach nefesh allows Jewish health care workers, on the Sabbath, to perform their jobs and others to summon ambulances using telephones although these "work tasks" are typically avoided among observant Jews (see Tip 2). ${ }^{8}$

Although pikuach nefesh is important, it is not an absolute value. Most seriously ill Jewish patients also wish to manage emotional suffering, uncontrolled physical symptoms, and apply a careful approach based upon how close a patient is to the end of life. The tradition teaches that human beings come from a divine source and that the lifespan should be supported in a dignified manner. When a palliative care clinician perceives that an observant Jewish patient is likely to die in a matter of days, this can be communicated as the religious status of imminent death (gesisah) and may imply that medical efforts toward life prolongation should be suspended and comfort-oriented measures should take precedence. ${ }^{9}$

\section{Tip 5: Jewish Patients May Be Wary of Non-Jewish Clinicians Asking About Faith due to a Collective and Intergenerational Trauma History}

The Jewish people have experienced a long history of violence and violation, often in the name of religion. ${ }^{10} \mathrm{Col}-$ lective and intergenerational trauma impacts the entire Jewish community, regardless of an individual's specific relationship to Judaism as a religion versus an ethnicity or culture (see Tip 1). Most Jewish people have experienced attempts at proselytizing and evangelizing. When a nonJewish provider asks a Jewish patient about faith, an internal response might be to wonder if the provider is asking for alienating reasons, such as an attempt to convert them.

To help Jewish patients feel safe, all providers should engage with an awareness that even a well-intentioned question about religion can stir intergenerational trauma. Whether direct descendants of Holocaust (Shoah) survivors or not, the trauma of threatened survival often looms for Jewish patients facing end-of-life decisions. To build trust, providers are encouraged to be explicit about the reason for asking about the patient's faith tradition or spiritual community. Being cognizant of one's own biases can help the palliative care clinician remain sensitive to the personal and intergenerational trauma of patients ${ }^{11}$ Engaging with curiosity, asking open-ended questions, and tolerating the potential suspicion and discomfort that might arise are key elements of supporting the spiritual lives of seriously ill Jewish patients. $^{12}$

\section{Tip 6: Orthodox Jewish-Identifying Patients May Have Specific Practical and Spiritual Issues in Serious IIIness and Dying}

Jewish patients who self-identify as Orthodox endeavor to conduct their daily lives in accordance with Jewish law, or halacha. Orthodox Jews may wish to consult a rabbi before making major life decisions, including health care choices. Each community may have their own rabbi, leading to a wide variation in practice within Orthodox Judaism. It would not be uncommon for two Orthodox Rabbis to advise differently on the same medical situation. ${ }^{13}$

Orthodox Jews and their families may request that the physician discuss medical details with the rabbi so that the rabbi may determine what is permissible through the lens of Jewish religious law. ${ }^{14}$ As Orthodox Jews value the sacredness of life, some interpretations mandate continuing lifeprolonging treatment unless the proposed measure also involves potential harm. To assist deliberation, Orthodox patients and families may request that palliative care clinicians provide the rabbi with pertinent details such as the patient's likely prognosis as well as the risks and benefits of a proposed treatment.

\section{Tip 7: Judaism Prescribes a Clear Set of Rituals before and after Death}

Judaism prescribes rituals related to dying and mourningsome Jewish patients and families do all, some a few, and still 
others, none. Before death, Jews recite a prayer called vidui (confession) where they acknowledge their imperfections and request forgiveness. Patients may recite vidui themselves or request a rabbi to perform this ritual on their behalf.

Upon hearing of a death, Jewish patients may respond, "Baruch dayan ha-emet" (Blessed is the One who judges truth). Judaism teaches that death marks the beginning of the separation of the body and soul; however, the separation is not considered complete until burial. Because the soul is thought to attend the body until that time, the deceased is never left unattended until burial (shmirah or watching). Jewish law prohibits cremation and, even among many less observant Jews, the practice evokes Holocaust trauma and is generally avoided. As soon as practically possible, Jewish community volunteers (chevra kadisha or sacred society) wash and prepare the patient's body for burial (taharah or purification). Within 72 hours, families often bury the deceased in an unadorned wooden casket, emphasizing the equality of all people. These practices concretize the death and transform the family members into mourners, a religious status with specific obligations.

The first week after death is called shiva (seven days), when the family stays home, receives visitors, and prays together with the community (although many of these rituals have been adapted virtually in the COVID-19 era). During the first month, sheloshim (30 days), the mourner returns to work and family roles with many restrictions, such as avoiding celebrations and hearing live music. Various mourning rituals, including the daily recitation of the kaddish prayer (a declaration of God's majesty recited at every prayer service) for close relatives, continue for 11 months after the death. After the yahrtzeit (death anniversary), the mourner fully reenters normal communal life and, thereafter, marks the person's death annually with a special candle that burns slowly for an entire day.

\section{Tip 8: Jews May Approach the Topic of Organ Donation with Religious Differences Depending on the Definition of Death}

Two main religious concepts, the obligation to save human life ( pikuach nefesh, see Tip 4) and the belief that all people are created in God's image (b'tzelem Elohim) apply to the issue of organ donation. Many Jews of differing observance levels believe that there is a moral imperative to take all action necessary to save a life and recognize that all human beings are sacred in both body and spirit. Many Jewish patients and families view organ donation favorably, as it respects the principle of saving life ( pikuach nefesh) by saving another person's life. However, ethical challenges may arise for some Orthodox Jewish families when clinicians propose the patient's removal from life-prolonging technology to facilitate the organ recovery. There can be no hastening of life's end, as such patients believe that longevity is solely in the hands of God.

Differing views over the definition of death (brain death vs. cardiorespiratory demise) comprise the main source of disagreement among Jewish communities. Patients who align with liberal Jewish movements or no denomination at all hold that death is defined as irreversible cessation of neurological activity, consistent with mainstream medical consensus. However, many individuals and rabbis in highly Orthodox
Jewish communities hold that only heart and lung standstill (as opposed to brain death) meets the criteria for death. Palliative care teams should involve Jewish clergy in these matters according to patient and family request.

\section{Tip 9: Many Jewish Patients Find Prayer to be an Important Aspect of Coping with Serious IIIness}

The Jewish tradition is rich with prayers around illness, death, and dying. There are stories from the Talmud detailing the perceived power of prayer for those suffering with serious illness. Many Jewish patients will find prayer to be a unique source of comfort in difficult times, whereas others will decline to engage in any form of devotion. The traditional prayer for healing invokes the Biblical ancestors and is called the Prayer for the Sick (mi shebeirach l'cholim). Some communities recite it entirely in Hebrew and others may sing arrangements mixed with English or the local language. Many Jewish patients connect deeply with this prayer even if they do not consider themselves to be otherwise observant. Although some may question if this prayer is appropriate for seriously ill patients for whom healing from disease seems unlikely, it is important to note that this prayer asks for both healing of the body and healing of the soul. Furthermore, it prays for a complete healing (r'fuah shleima) and is connected to a wish for wholeness and peace. Community members also recite this prayer during synagogue services, often naming the person publicly, which can bring the ill person into the awareness of other individuals who may offer spiritual, social, or other practical support.

\section{Tip 10: Jewish Patients Hold Differing Views on the Afterlife}

Jewish patients hold a wide variety of beliefs about what happens after bodily death, ranging from mystical (kabbalistic) concepts of reincarnation to concrete accounts of heaven and hell. Many Jewish patients also do not believe in the afterlife and others do not know what the Jewish tradition holds, as it is not frequently discussed. Jewish teachings often focus strongly on living an ethical life in the here and now. However, many Jewish patients may be curious about what happens after death and what their faith tradition says about it. Numerous texts suggest a world to come (olam haba) where there may be resurrection of the dead, particularly those individuals who have behaved righteously during their lifetime. There are few mentions of a hell known as gehennom, mentioned as an inferno where final judgement occurs, described in the Talmud as "sixty times hotter than fire on earth" with a more desirable alternative of a Garden of Eden-like environment for the virtuous. ${ }^{15}$

As there are limited mentions of the afterlife in Jewish texts, seriously ill patients may draw ideas from secular or non-Jewish religious sources. Palliative care clinicians should use a curiosity approach when discussing the afterlife with Jewish patients and be open to exploring a topic that may be experienced as unknown and potentially distressing.

\section{Conclusion}

Jewish patients vary widely in their identities, beliefs, and practices. This diversity has major implications for providing 
their serious illness and end-of-life care. As the Jewish American population grows in numbers and ages in years, palliative care clinicians benefit from a fuller and more nuanced understanding of cultural and religious aspects of Judaism that pertain to health care decisions, inpatient care, and bereavement.

\section{Funding Information}

Andrea W. Schwartz: Some of this material is the result of work supported with resources and the use of facilities at the Veterans Health Administration Boston Medical Center and the New England Geriatric Research Education and Clinical Center. The views expressed in this article are those of the authors and do not necessarily reflect the position or policy of the Department of Veterans Affairs or the United States government.

\section{Author Disclosure Statement}

No competing financial interests exist.

\section{References}

1. Waldoks M, Novak W (eds.): Introduction. In: The Big Book of Jewish Humor. New York: HarperCollins Publishers, William Morrow Paperbacks, 2006.

2. Genesis 2: 1-3. Hebrew Bible.

3. Rose A: Caring for the Orthodox Jewish patient on the Sabbath. Acad Emerg Med 1999;6:865-866.

4. Eriksson A, Burcharth J, Rosenberg J: Animal derived products may conflict with religious patients' beliefs. BMC Med Ethics 2013;14:48.

5. Easterbrook C, Maddern G: Porcine and bovine surgical products: Jewish, Muslim and Hindu perspectives. Arch Surg 2008;143:366-370.
6. Rosner F: Pig organs for transplantation into humans: A Jewish view. Mt Sinai J Med 1999;66:314-319.

7. Leviticus 18:5. Hebrew Bible.

8. Shulchan Aruch 328:13.

9. Bressler T, Popp B: Ethical challenges when caring for orthodox Jewish patients at the end of life. J Hosp Palliat Nurs 2018;20:36-44.

10. Weinrach SG: The counseling profession's relationship to Jews and the issues that concern them: More than a case of selective awareness. J Couns Dev 2002;80:300-314.

11. Weiss T: Caring for Holocaust Survivors and Survivors of Other Traumatic Events at the End of Life. Alexandria, VA: National Hospice and Palliative Care Organization Palliative Care Resource Series, 2016.

12. Johnston Taylor E: Religion: A Clinical Guide for Nurses. New York: Springer Publishing Company, 2012.

13. Loike J, Gillick M, Mayer S, et al.: The critical role of religion: Caring for the dying patient from an Orthodox Jewish perspective. J Palliat Med 2010;13:1267-1271.

14. Linzer RD: Treatment of terminally ill patients according to Jewish law. Virt Mentor 2013;15:1081-1087.

15. Talmud, Berakhot 57b.

Address correspondence to:

Leah B. Rosenberg, MD

Division of Palliative Care and Geriatric Medicine Massachusetts General Hospital 55 Fruit Street, Austen 600 Boston, MA 02114

USA

E-mail: leah_rosenberg@dfci.harvard.edu 